\title{
RETOS DE LA SALUD OCUPACIONAL Y DE LA PROTECCIÓN AMBIENTAL A INICIOS DEL SIGLO XXI EN EL PERÚ
}

\author{
Estela Ospina ${ }^{1, a} ;$ Ronald Bautista ${ }^{1, b} ;$ Liliana Vigil $^{1, c} ;$ Juan Diaz ${ }^{1, d}$ \\ GOALS OF OCCUPATIONAL HEALTH AND ENVIRONMENTAL \\ PROTECTION AT THE BEGINNING OF THE 21ST CENTURY IN PERU
}

\begin{abstract}
La salud ocupacional y la protección del ambiente para la salud de las poblaciones en el Perú, es una de las prioridades dentro de la política nacional para el desarrollo sostenible del país. El crecimiento económico y productivo de bienes y servicios del Perú durante estos últimos años, tiene uno de sus soportes en las exportaciones de diversos productos mineros y agropecuarios, lo cual genera importantes divisas, y el ingreso de nuestros productos a los principales mercados internacionales. Un incremento de la producción en las actividades laborales implica la exposición a diversos riesgos ocupacionales que afectarían la salud no solo del trabajador, si no también la de sus familias y del medioambiente. Esto conlleva la evaluación y supervisión permanente de los posibles riesgos que podrían afectar la salud de la población, lo cual permitirá garantizar la seguridad y salud de los trabajadores, el cuidado del medio ambiente y la eficacia de los procesos productivos.
\end{abstract}

La galería fotográfica que se presenta da a conocer un acercamiento al mundo del trabajo a inicios del siglo XXI (1) en el Perú. El Centro Nacional de Salud Ocupacional y Protección del Medio Ambiente para la Salud (CENSOPAS) del Instituto Nacional de Salud (INS), está dedicado a realizar investigaciones y recomendaciones para la prevención de enfermedades, y lesiones originadas por actividades laborales, las que pueden afectar a los trabajadores y a la comunidad. Por ello, se promueve la investigación para la protección de la salud ocupacional y de las comunidades; así como se trabaja bajo el principio preventivo y de cuidado del entorno, a fin de contribuir con el desarrollo sostenible y la conservación del medioambiente para las futuras generaciones.
Las fotografías mostradas fueron obtenidas en actividades de campo, e incluidas como parte de los informes de actividades.

\section{AGROINDUSTRIA}

El incremento de la agroexportación peruana dinamizó la actividad en el campo y el transporte de los productos, lo que implica diversos riesgos laborales para el trabajador ya sea en el aspecto ergonómico, por la carga física y posturas extremas prolongadas; por exposiciones a sustancias químicas, entre otros.

También, la protección de la salud laboral de trabajadores en cultivos de arroz, implica la evaluación de diversos parámetros tanto en el trabajador, a través de la medición del estrés térmico durante la actividad laboral (presión

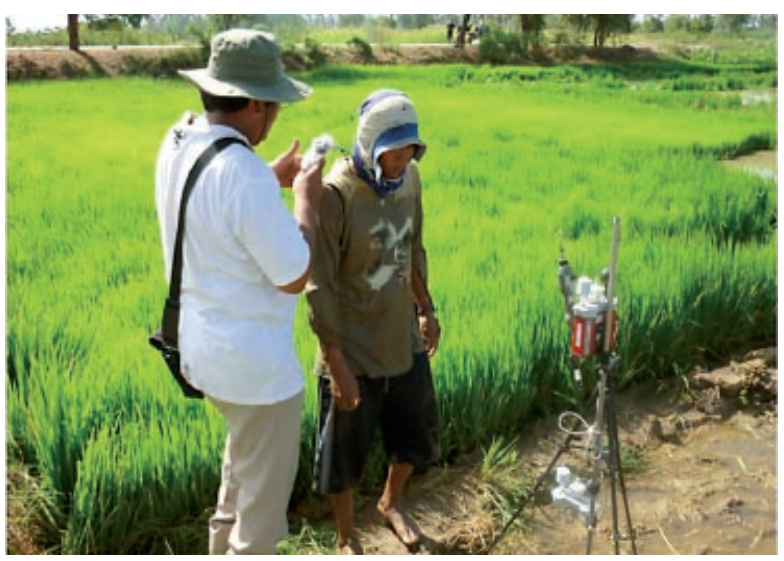

Figura 1. Evaluación de salud laboral de trabajadores en cultivos de arroz.

\footnotetext{
Centro Nacional de Salud Ocupacional y Protección del Ambiente para la Salud, Instituto Nacional de Salud. Lima, Perú.

Abogada máster en Prevención de Riesgos Laborales; ${ }^{\mathrm{b}}$ tecnólogo médico magíster en Bioquímica y Biología Molecular; ${ }^{\mathrm{c}}$ psicóloga del trabajo magíster en Salud Ocupacional; ${ }^{\mathrm{d}}$ técnico de laboratorio.
} 


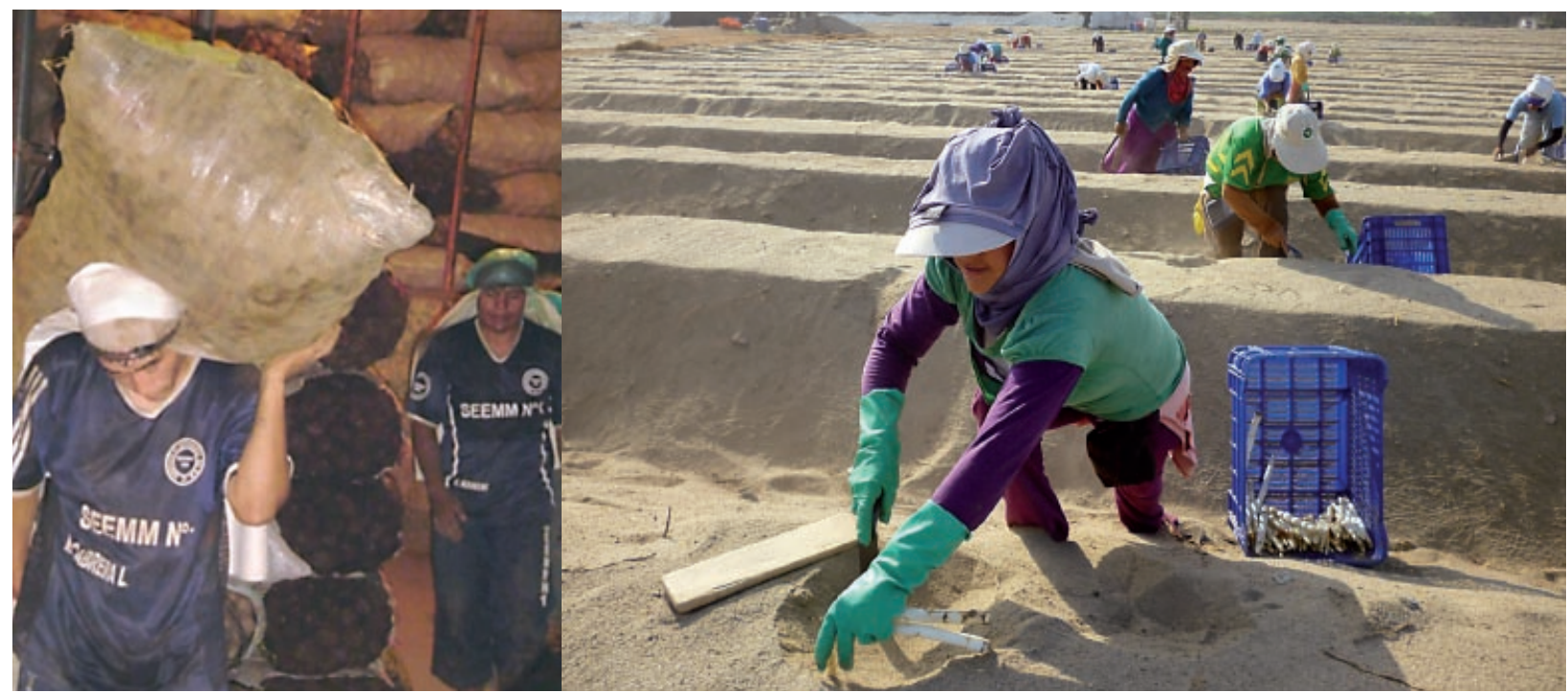

Figura 2. Riesgos laborales en la agroindustria: ergonómicos y de exposición a sustancias químicas.

sanguínea, temperatura corporal), como del ambiente (radiación, humedad, velocidad del viento).

\section{MINERÍA}

El sector minero en el Perú presenta un significativo número de trabajadores expuestos a diversas condiciones físicas, químicas, disergonómicas, ambientales, entre otras. Parte de las evaluaciones médicas incluyen elaborar un perfil antropométrico.

Las evaluaciones médicas en pobladores de las comunidades aledañas a proyectos mineros, se realizan con el fin de identificar en forma precoz, posibles alteraciones temporales, permanentes o agravadas del estado de salud de la población, como parte del impacto probable de la actividad minera. Estas incluyen evaluaciones de salud mental para adultos y niños.
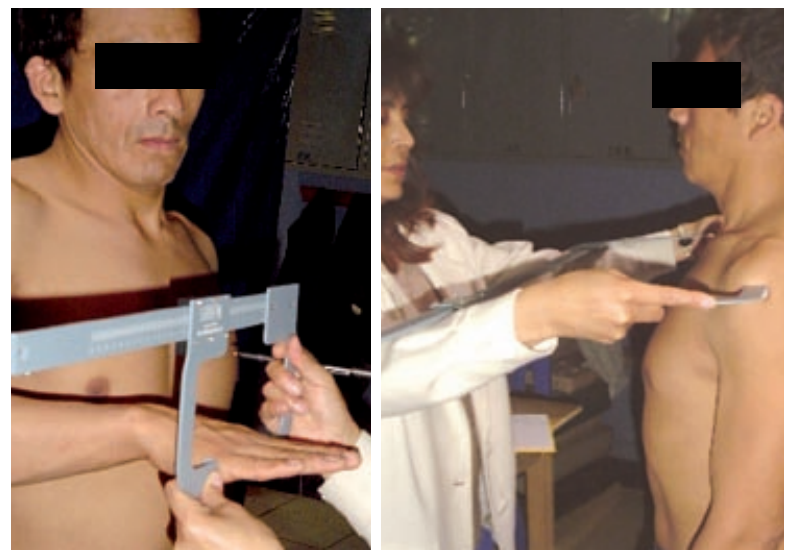

Figura 3. Evaluación antropométrica en mineros.

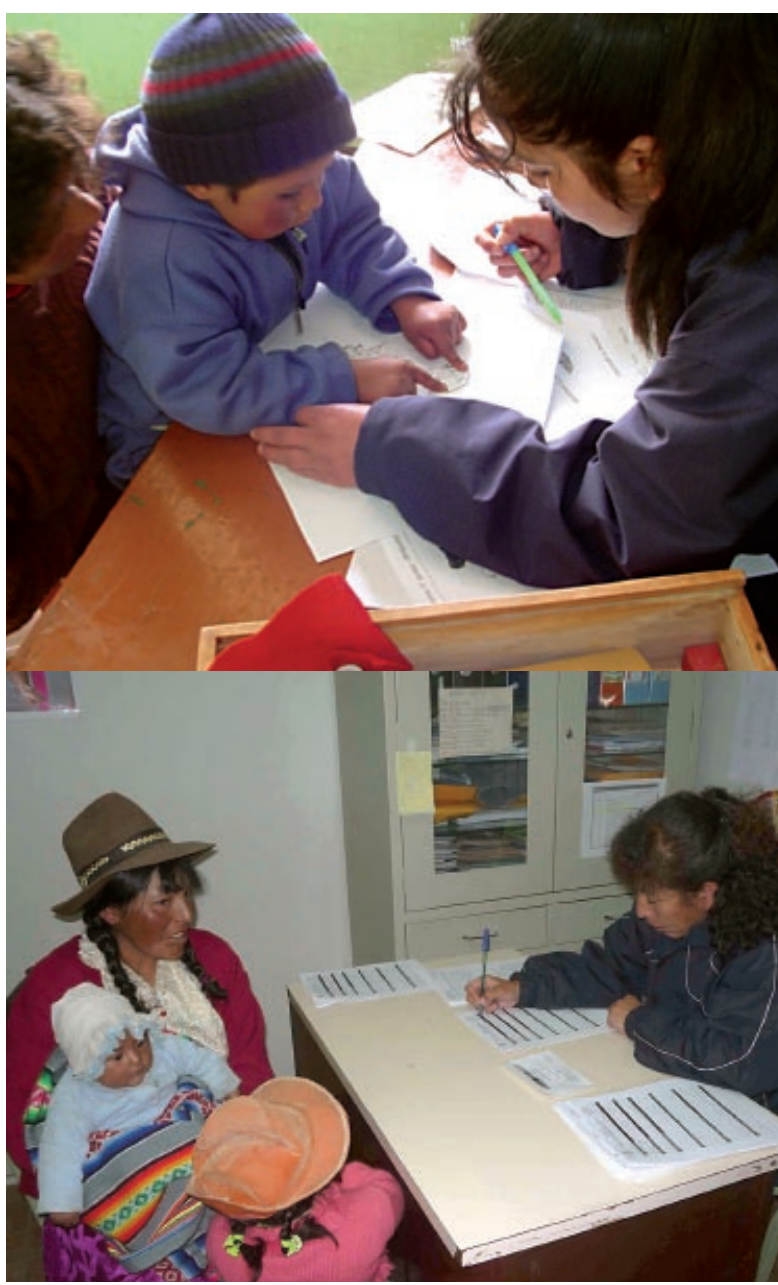

Figura 4. Evaluación médica y psicológica en pobladores de comunidades cercanas a proyectos mineros 


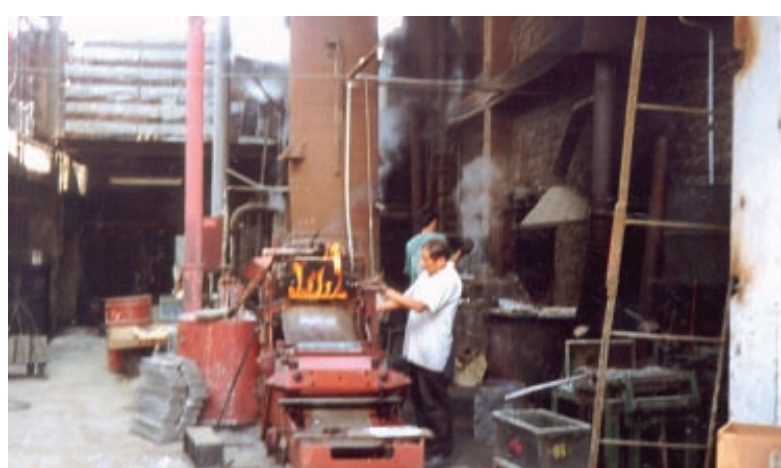

Figura 5. Fundición de plomo en fábrica de baterías.

\section{INDUSTRIA}

El personal que labora en estas fundiciones es una población de alto riesgo, debido a la exposición permanente al plomo y a otros metales contaminantes.

\section{RETOS DE LA SALUD OCUPACIONAL}

En las actividades de campo, el personal de CENSOPASINS debe adaptarse a las condiciones ambientales y geográficas para realizar la evaluación médica de los trabajadores en plena actividad laboral.

También se realizan mediciones de parámetros bioquímicos en la población aledaña a los proyectos

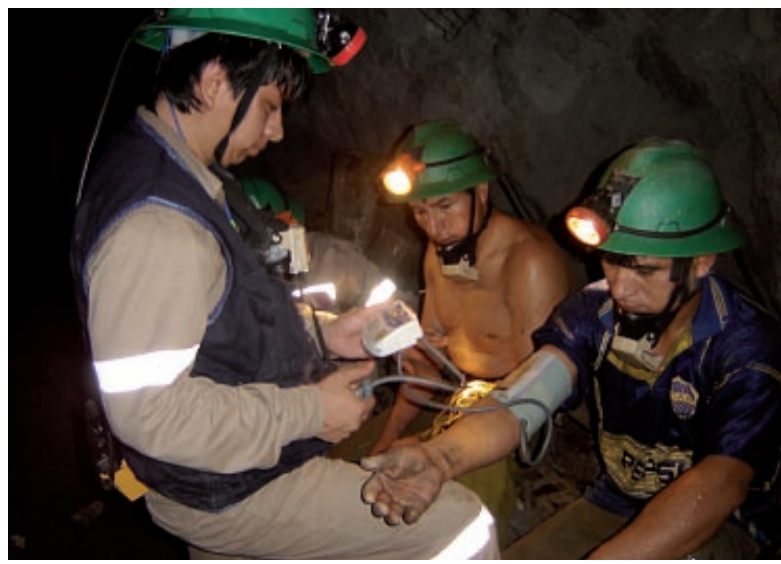

Figura 6. Acercamiento a los trabajadores mineros dentro del socavón. mineros; para ello, el personal debe adaptarse a las limitaciones de infraestructura, sin perder la calidad en la atención.

Por último, el CENSOPAS-INS brinda servicios de análisis en los dos laboratorios: clínico y químico toxicológico. En ambos casos, un reto fundamental es garantizar que la toma de muestras se realice según procedimientos con estándares internacionales, y con una cadena de custodia que permitan asegurar un alto grado de confiabilidad. En los laboratorios se realiza la evaluación de muestras biológicas, evaluación de agentes contaminantes de muestras ambientales, determinación de solventes, gases y vapores en muestras atmosféricas, plaguicidas y otros compuestos orgánicos. El personal altamente calificado procesa los análisis bajo los criterios de NTP:ISO 15189 y la NTP:ISO 17025; para la parte clínica y toxicológica, respectivamente.

\section{REFERENCIAS BIBLIOGRÁFICAS}

1. Organización Internacional del Trabajo (OIT). Programa de Seguridad y Salud en el Trabajo y Medio Ambiente (Safe Work). 1ra edición. Ginebra: OIT; 2012.

Correspondencia: Estela Ospina Salinas

Dirección: Cl. Las Amapolas 350, Urb. San Eugenio, Lima 14, Perú. Teléfono: (511) 617-6177 Anexo 7726.

Correo electrónico: eospina@ins.gob.pe

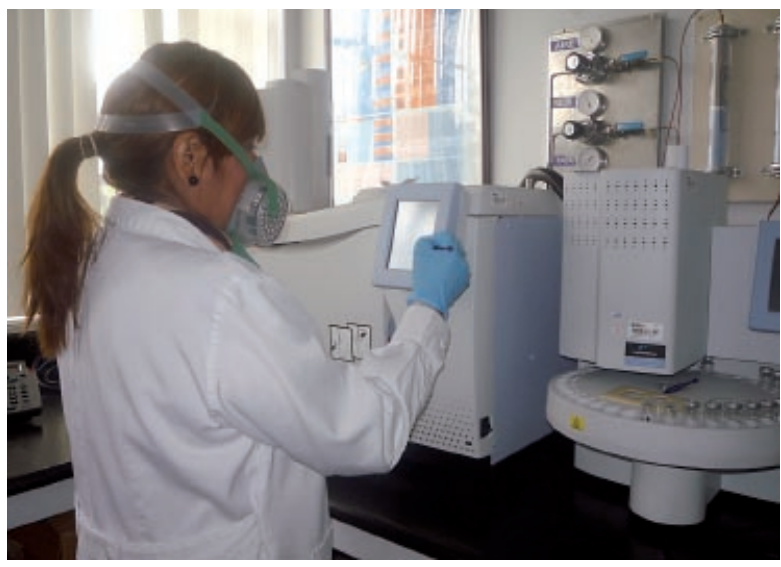

Figura 7. Análisis químico toxicológico en elCentro Nacional de Salud Ocupacional y Protección del Ambiente para la Salud. 